\title{
Entre a legislação, a experiência e a subjetividade: a adoção para profissionais do Sistema de Justiça
}

\author{
Between legis/ation, experience and subjectivity: adoption for professionals in the Justice \\ System
}

\author{
Kamyla Ribeiro Dornelas dos Santos* \\ Mariana Silva Cecílio** \\ Fabio Scorsolini-Comin***
}

\section{Resumo}

O presente estudo qualitativo buscou compreender os significados atribuídos à adoção por parte dos profissionais que atuam no Sistema de Justiça. Participaram 41 profissionais (seis juízes, três promotores, 14 psicólogas e 18 assistentes sociais) provenientes de 10 comarcas de três diferentes Estados (São Paulo, Minas Gerais e Goiás) que responderam a um roteiro de entrevista semiestruturado. O corpus composto pelas entrevistas audiogravadas e transcritas foi submetido à análise temática e interpretado pela literatura da área de adoção. A maioria dos entrevistados relacionou a adoção a questões afetivas. Contudo, foi possível perceber um resquício da visão de adoção como algo que supre o que foi biologicamente impossibilitado. Em que pesem as possíveis dicotomias existentes entre os critérios técnico-legais e subjetivos dos profissionais de Justiça, recomenda-se que a subjetividade desses profissionais possa ser considerada inerente a esse fazer, atravessando os processos de avaliação e de decisão quanto a adoção. Aponta-se para a necessidade de reconhecimento desses aspectos, permitindo uma prática mais amadurecida e igualmente comprometida com os marcadores legais do processo e com os interesses das crianças e adolescentes, promovendo adoções seguras e bem-sucedidas.

Palavras-chave: Adoção. Psicologia jurídica. Processos legais.

\section{Abstract}

The aim of this qualitative study was to understand the meanings attributed to adoption by professionals working in the Justice System. 41 professionals participated (six judges, three prosecutors, 14 psychologists and 18 social workers) from three different Brazilian states (São Paulo, Minas Gerais and Goiás) who responded to a semi-structured interview script. The corpus composed of audiorecorded and transcribed interviews was subjected to thematic analysis and interpreted by the literature in the area of adoption. Most respondents related adoption to affective issues. However, it was possible to perceive a trace of the adoption view as something that supplies what was biologically impossible. In spite of the possible dichotomies existing between the technical-legal and subjective criteria of the legal professionals, it is recommended that the subjectivity of these professionals can be considered inherent to this doing, going through the evaluation and decision processes regarding the adoption. It points to the need to recognize these aspects, allowing for a more mature practice and equally committed to the legal markers of the process and to the interests of children and adolescents, promoting safe and successful adoptions.

Keywords: Adoption. Meaning. Juridical psychology. Legal processes

\footnotetext{
* Psicóloga pela Universidade Federal do Triângulo Mineiro, Uberaba-MG, Brasil.

** Psicóloga e Mestra em Psicologia pela Universidade Federal do Triângulo Mineiro. Docente da Universidade de Uberaba, Uberaba-MG, Brasil.

*** Psicólogo, Mestre e Doutor em Psicologia pela Universidade de São Paulo. Docente do Departamento de Enfermagem Psiquiátrica e Ciências Humanas da Escola de Enfermagem de Ribeirão Preto da Universidade de São Paulo, Ribeirão Preto-SP, Brasil. Bolsista de Produtividade em Pesquisa do CNPq.
} 
Para compreendermos o panorama atual da adoção no Brasil e os seus significados ao longo da história é mister abordarmos as mudanças históricas, sociais e culturais que atravessam esse campo. Desde o Código Civil de 1916 até a Lei no 12.010/09 evidencia-se uma gradativa mudança no foco das adoções (VALÉRIO; LYRA, 2016). No Código Civil, Lei 3.071 de 1916, a adoção só era permitida para pessoas com mais de 50 anos, sem filhos e poderia ser revogada a qualquer momento. Além disso, não priorizava o interesse da criança (PEREIRA; AZAMBUJA, 2015; WEBER, 2001), haja vista que permitia que houvesse discriminação entre filhos consanguíneos e adotivos.

De acordo com Weber (1998), a história da adoção pode ser dividida em dois momentos, a "Adoção Clássica" e a "Adoção Moderna". A primeira tinha como objetivo dar filhos a casais com infertilidade (COSTA; ROSSETTI-FERREIRA, 2007), sendo que o filho por adoção não rompia completamente o vínculo com a família consanguínea. Já a adoção Moderna procura resolver o problema da criança sem família, buscando uma família substituta para crianças que se encontram em situação de abandono (WEBER, 1998). A Lei no 6.697/79 do Código de Menores estabeleceu duas formas de adoção: simples e plena. Na adoção simples formava-se um laço de paternidade limitado, pois o filho por adoção não se desligava da família consanguínea. Já na adoção plena havia a desvinculação com a família de origem, ou seja, era irrevogável. Porém, era destinada exclusivamente a crianças menores de sete anos e em situação de abandono (PEREIRA; AZAMBUJA, 2015; WEBER, 2001).

O Estatuto da Criança e do Adolescente (ECA), Lei 8.069 de 1990, foi de extrema importância para reconhecer a adoção como ato de filiação e parentalidade que envolve aspectos legais, sociais e afetivos, bem como por estabelecer a igualdade entre filhos consanguíneos e por adoção. O ECA também pôs fim à adoção simples, mantendo apenas a adoção plena e irrevogável para crianças e adolescentes menores de 18 anos (MERÇONVARGAS; ROSA; DELL'AGLIO, 2015; PEREIRA; AZAMBUJA, 2015; WEBER, 2001). A adoção passou a ser tratada como medida de proteção em caráter excepcional quando esgotados os recursos de manutenção da criança e do adolescente na família natural ou extensa (BRASIL, 1990), bem como ato de filiação e parentalidade que envolve aspectos legais, sociais e afetivos (CAMPOS; COSTA, 2004).

Concomitantemente às mudanças de ordem legal, pode-se afirmar que, gradativamente, tem havido uma mudança na cultura da adoção em nosso país, contribuindo 
para a desconstrução de mitos e crenças que perpassam o imaginário social (SCHETTINI; AMAZONAS; DIAS, 2006). Ela já não é mais vista como último recurso para quem quer ter filhos, mas como uma das principais possibilidades de constituição familiar (OTUKA; SCORSOLINI-COMIN; SANTOS, 2009; SCHETTINI; AMAZONAS; DIAS, 2006). Além disso, outras motivações que não a infertilidade dos postulantes passaram a emergir e ter maior visibilidade, como a busca pela adoção por parte de pessoas solteiras, viúvas, casais não estéreis e pares do mesmo sexo, por exemplo (CECÍLIO; SCORSOLINI-COMIN, 2018a; VALÉRIO; LYRA, 2016). Outro fator importante que tem contribuído para a desestigmatização da família composta por adoção e para a concretização de uma cultura de adoção que não seja norteada por laços consanguíneos, mas sim por laços afetivos, são os grupos de apoio à adoção (MERÇON-VARGAS; ROSA; DELL'AGLIO, 2015; SCHETTINI; AMAZONAS; DIAS,2006).

O processo de habilitação para a adoção ocorre com a participação de diferentes profissionais, entre eles o psicólogo e o assistente social, que formam o corpo técnico de assessoramento e perícia e realizam a avaliação psicossocial. Além desses profissionais existe a figura do promotor, responsável pela fiscalização e análise dos fatores legais relacionados ao processo de adoção e, por fim, o juiz, que confere o parecer final (CAMPOS; COSTA, 2004; FERREIRA, 2001; WEBER, 2001).

Especificamente acerca do papel dos assistentes sociais e dos psicólogos, há o atendimento à família de origem e extensa, a organização de encontros preparatórios dos interessados em adotar, a avaliação dos candidatos na habilitação para a adoção, bem como a realização de pesquisas nos cadastros de adoção no decorrer da procura de famílias substitutas (SÃO PAULO, 2007). Também são responsáveis pelo acompanhamento das crianças e adolescentes com perspectiva de colocação em família substituta através da adoção e o acompanhamento do estágio de convivência. Weber (2001) aponta que no processo de adoção os profissionais do Sistema de Justiça têm a oportunidade de realizar um trabalho educativo com esses candidatos, buscando esclarecer os mitos sobre a adoção, minimizar os preconceitos e mostrar que a filiação consanguínea não é a única forma de parentalidade.

Oliveira (2014) nos traz que o promotor possui a função da defesa da ordem jurídica, do regime democrático e dos interesses sociais e individuais indisponíveis. Assim, é o responsável pelas questões legais e pela abertura dos processos para habilitação de candidatos à adoção. É importante ressaltar também que ele possui outras tarefas, como a 
aplicação e manutenção dos direitos das crianças e dos adolescentes, pautando-se no que é estabelecido pelo ECA. Esta autora aponta que o papel do Juiz se refere a uma análise de provas que são submetidas no decorrer do processo. Essas provas são estudos psicossociais, como pareceres ou laudos formulados por profissionais, como psicólogos e assistentes sociais.

Buscando compreender melhor o papel desta equipe no que refere ao processo de adoção, percebe-se que algumas barreiras precisam ser problematizadas. Campos e Costa (2004) e Weber (2001) sugerem a necessidade de que a avaliação psicossocial seja um momento não apenas de seleção, mas de construção de um espaço de preparação para a adoção. Para que isso ocorra, o profissional deve deixar a posição de especialista, atuando como um mediador e facilitador de reflexões e mudanças junto aos postulantes. Para além da necessidade de indicar se um postulante está apto ou não à adoção, o profissional deve ter a oportunidade de compreender melhor o que esse ato representa, reconhecendo os aspectos subjetivos que atravessam o seu fazer (WEBER, 2001).

Esses elementos subjetivos que atravessam e que compõem o fazer profissional nesse campo são construídos tanto por aspectos individuais como por marcadores sociais e culturais, em uma perspectiva histórico-cultural da subjetividade. Enquanto processo, a subjetividade não poderia ser reduzida aos aspectos individuais e intrapsíquicos do sujeito nem determinada pelos seus contextos de interação e de produção, recusando também as clássicas dicotomias entre cognitivo e afetivo, consciente e inconsciente, por exemplo: "a subjetividade é um sistema complexo que tem dois espaços de constituição permanente e inter-relacionados: o individual e o social, que se constituem de forma recíproca e, ao mesmo tempo, cada um está constituído pelo outro." (GONZÁLEZ REY, 2004, p. 141).

Essa perspectiva processual acena para a necessidade de que a subjetividade desses profissionais possa ser reconhecida, problematizada, mas não escamoteada, considerando que nenhuma prática profissional e de produção no mundo pode ser apartada dessa condição. As ações dos profissionais do Sistema de Justiça, nessa perspectiva, são fontes dos processos de subjetivação que se materializam na sua experiência - no caso, da avaliação e decisão sobre os processos de adoção.

A literatura produzida junto aos membros da equipe psicossocial destaca que a avaliação pode ser permeada pela subjetividade desses profissionais sem, no entanto, problematizar esse conceito (CECÍLIO; SCORSOLINI-COMIN, 2018b; VALÉRIO; LYRA, 2016; 
WEBER, 2001; XIMENES; SCORSOLINI-COMIN, 2018). Nessa perspectiva abordada na literatura, a subjetividade acaba sendo tomada como sinônimo ora de preponderância de aspectos individuais, ora de determinações sociais e culturais que atravessam o fazer profissional, permitindo a emergência de discussões que destacam os possíveis abusos de poder e as expressões de preconceitos em relação à adoção nesse fazer (CAMPOS; COSTA, 2004).

Entretanto, não foram encontrados estudos específicos que retratam as percepções dos profissionais do Sistema de Justiça em relação aos significados da adoção nem como as suas subjetividades podem compor esse fazer. A partir disso, torna-se relevante estudar essa temática para compreender se e de que modo a subjetividade pode influenciar no processo de avaliação e na posterior tomada de decisão sobre a efetivação da adoção. Sendo assim, o presente estudo buscou compreender os significados atribuídos à adoção por parte dos profissionais que atuam no Sistema de Justiça: juízes, promotores, assistentes sociais e psicólogos.

\section{Método}

Tipo de estudo e aspectos éticos

Trata-se de um estudo exploratório com base na abordagem qualitativa de pesquisa, aprovado pelo Comitê de Ética em Pesquisa da instituição de origem da primeira autora (Parecer 2360/2012). Os participantes do estudo e as comarcas não serão identificados neste estudo, sendo utilizados nomes fictícios.

Participantes

Participaram 41 profissionais que atuam no Sistema de Justiça, sendo seis juízes, três promotores, 14 psicólogas e 18 assistentes sociais. Optou-se por profissionais que participavam ativamente dos processos de avaliação e/ou decisão de capacitar casais para adoção. Foram realizadas entrevistas em 10 comarcas pertencentes a três estados diferentes (Minas Gerais, São Paulo e Goiás), adotando-se o critério de saturação. O Quadro 1 sumariza as informações sobre os participantes.

Quadro 1 - Identificação dos profissionais ( $n=41)$

\begin{tabular}{|c|c|c|c|c|c|}
\hline $\begin{array}{c}\text { Categoria } \\
\text { Profissional }\end{array}$ & $\begin{array}{c}\text { Média } \\
\text { de } \\
\text { Idade }\end{array}$ & Estado Civil & $\begin{array}{c}\text { Média de } \\
\text { Filhos }\end{array}$ & $\begin{array}{c}\text { Crença Religiosa/ } \\
\text { Espiritual }\end{array}$ & $\begin{array}{c}\text { Média tempo de } \\
\text { formação/média } \\
\text { de tempo } \\
\text { no cargo }\end{array}$ \\
\hline
\end{tabular}




\begin{tabular}{|c|c|c|c|c|c|}
\hline Juízes ( $n=6$ ) & $\begin{array}{l}47,16 \\
\text { anos }\end{array}$ & $\begin{array}{l}\text { Casado (5), } \\
\text { Separado (1) }\end{array}$ & $\begin{array}{c}2,5 \\
\text { [1 possui } \\
\text { filho por } \\
\text { adoção] }\end{array}$ & $\begin{array}{l}\text { Católico (3), Espírita } \\
\text { (1), Não possui (1), Não } \\
\text { identificou (1) }\end{array}$ & $\begin{array}{l}20,16 \text { anos/ } \\
13,16 \text { anos }\end{array}$ \\
\hline $\begin{array}{l}\text { Promotores } \\
(n=3)\end{array}$ & $\begin{array}{l}43,6 \\
\text { anos }\end{array}$ & $\begin{array}{l}\text { Todos } \\
\text { casados }\end{array}$ & $\begin{array}{c}1,33 \\
\text { [1 possui } \\
\text { filho por } \\
\text { adoção] }\end{array}$ & $\begin{array}{l}\text { Espírita (1), Não possui } \\
\text { (1), Não identificou (1) }\end{array}$ & $\begin{array}{c}21 \text { anos/ } \\
15,33 \text { anos }\end{array}$ \\
\hline $\begin{array}{l}\text { Assistentes } \\
\text { Sociais } \\
(n=18)\end{array}$ & $\begin{array}{l}41,61 \\
\text { anos }\end{array}$ & $\begin{array}{c}\text { Casado (9), } \\
\text { Solteiro (6), } \\
\text { Separado (2), } \\
\text { Viúvo (1) }\end{array}$ & $\begin{array}{c}1,27 \\
{[2} \\
\text { possuem } \\
\text { filhos por } \\
\text { adoção] }\end{array}$ & $\begin{array}{c}\text { Católico (6), Evangélico } \\
\text { (1), Espírita (4), } \\
\text { Espiritualista (3), } \\
\text { Agnóstico (1), Não } \\
\text { possui/identificou (3) }\end{array}$ & $\begin{array}{c}18,72 \text { anos } / 9,91 \\
\text { anos }\end{array}$ \\
\hline $\begin{array}{l}\text { Psicólogos } \\
(n=14)\end{array}$ & $\begin{array}{c}44,8 \\
\text { anos* }\end{array}$ & $\begin{array}{l}\text { Casado (7), } \\
\text { Solteiro (3), } \\
\text { União } \\
\text { Estável (2), } \\
\text { Separado (1), } \\
\text { Viúvo (1) }\end{array}$ & 1,53 & $\begin{array}{c}\text { Católico (7), Não } \\
\text { possui/identificou (5), } \\
\text { Espírita (2) }\end{array}$ & $\begin{array}{c}18 \text { anos } / 12,89 \\
\text { anos }\end{array}$ \\
\hline
\end{tabular}

*Duas profissionais não quiseram informar a sua idade.

Fonte: Dados da pesquisa

\section{Instrumento}

Foi utilizado um roteiro de entrevista semiestruturado desenvolvido para este estudo contendo questões relacionadas ao significado de adoção, experiência do profissional na área, bem como a maneira com que realiza seu trabalho, sentimentos vivenciados ao lidar com esta temática, possível influência de suas crenças e concepções nas tomadas de decisão, bem como as dificuldades encontradas.

\section{Procedimento}

Os participantes do estudo foram encontrados a partir de um grupo de apoio à adoção e de contatos sociais estabelecidos pelo grupo de pesquisa de origem dos autores. Com cada participante, após a assinatura do Termo de Consentimento Livre e Esclarecido, houve a realização da entrevista individual no local de trabalho do voluntário, em sala reservada. As entrevistas foram audiogravadas e posteriormente transcritas na íntegra, compondo o corpus analítico. Primeiramente, foi realizada análise vertical das entrevistas que compuseram o corpus, buscando compreender a fala dos profissionais acerca do tema abordado. Posteriormente foi feito um recorte do estudo, a fim de selecionar apenas os trechos que tratavam dos significados da adoção. Por fim, foi realizada uma análise horizontal, 
permitindo a comparação entre os discursos dos diferentes profissionais. Foi empregada a análise temática (BRAUN; CLARKE, 2006), dividida nas seguintes etapas: familiarização com os dados, geração códigos iniciais, busca de temas, revisão temática, definição e nomeação de temas, e produção do relatório. A interpretação dos temas ocorreu a partir da literatura da área de adoção e família.

\section{Resultados e Discussão}

A partir da análise foram produzidos dois temas que possibilitam a compreensão de como os juízes, promotores, psicólogos e assistentes sociais percebem o ato da adoção e como suas vivências e subjetividades possivelmente influenciam nas suas percepções sobre esse ato, sobre o processo de avaliação psicossocial e a consequente tomada de decisão. Esses temas serão apresentados e discutidos a seguir.

\section{Atribuindo significados à adoção}

Neste tema será discutida a forma como os profissionais significam a adoção, investigando semelhanças e diferenças em seus discursos e se os mesmos vão ao encontro com o que é descrito pela legislação e literatura atual. Pensando no sentido da legislação mais atualizada sobre adoção, Lei 12.010/09 e o ECA, que preconizam o direito da criança e do adolescente a ter uma convivência familiar (BRASIL, 2009), foi possível perceber nas falas de sete profissionais que "a adoção é um ato de direito, é direito da criança e do adolescente ter uma família" (Luzia, assistente social). A fala de outro profissional vem para complementar, considerando que "a adoção é uma modalidade de colocação de crianças em família substituta. Sob a minha ótica de juiz de infância e juventude, a adoção é um recurso posto à disposição de crianças e adolescentes pra que eles encontrem famílias" (Fernando, juiz).

O ECA, enquanto protetor dos direitos das crianças e jovens, transforma a maneira como a adoção vinha sendo encarada e propõe que ela sempre vise ao melhor interesse desse público. A adoção, com o tempo, vem desfazendo preconceitos acerca da inferioridade do filho por adoção, e atribuindo novos significados à parentalidade, colocando as crianças e adolescentes como o foco principal de cuidado (COSTA; ROSSETTI-FERREIRA, 2007). Essa transformação pode ser evidenciada no modo como os entrevistados percebem a adoção: 
Às vezes as pessoas chegam com aquele sonho, aquela coisa de adoção, como algo pra suprir na vida deles, assim. E a gente tendo o foco na criança, no que vai ser melhor pra criança, faz toda diferença. E os casais tem muita dificuldade de entender isso, né (Amanda, assistente social).

Costa e Rossetti-Ferreira (2007) ressaltam que vivemos por muito tempo em um movimento de adoção que priorizava os interesses dos pretendentes. Esse fator ainda deixa resquícios, causando certa dificuldade para que as pessoas possam significar a adoção de uma forma diferente, voltada para os interesses das crianças ou adolescentes e que eles sejam vistos como sujeitos de direitos.

Percebeu-se no discurso de duas profissionais a importância de se trabalhar também a demanda da família, que muitas vezes chega fragilizada até a equipe técnica para o processo de habilitação à adoção. No entanto, essas profissionais ressaltam que é importante colocar as necessidades da criança como prioridade: “(...) a adoção só se dá quando há interesse das pessoas que buscam a adoção, então se a gente só priorizar o interesse da criança não vai chegar à uma família" (Victória, psicóloga). Apesar de na lei prevalecer o melhor interesse da criança/adolescente, na prática os profissionais entrevistados não conseguem seguir irrestritamente essa orientação. O Cadastro Nacional de Adoção, instituído pela Lei 12.012/09, ajuda a agrupar os perfis dos pretendentes com as crianças que estão disponíveis para adoção no país, mas existe uma grande divergência entre os perfis disponíveis e o perfil que os pretendentes procuram (SILVA et al., 2017). Ainda prevalece a necessidade de olhar para o desejo e a vontade dos pretendentes para que o processo de colocação da criança em família substituta seja concluído e diminuam os riscos da dissolução da adoção.

A maioria dos entrevistados ( $n=22$ ) significou a adoção de uma forma que transcende o que é dito pela legislação. Trouxeram aspectos mais afetivos e emocionais que são fundamentais para eles no momento de avaliar se o(s) candidato(s) estão aptos ou não a adotar. Para esses profissionais, a adoção está relacionada com: vinculação, afetividade, acolhimento, amor, cuidado, desejo, proteção e carinho. Um dos profissionais define que "[...] adoção é a escolha de ter um filho, de ter a possibilidade do acolhimento, a possibilidade de complemento [...], porque quem escolhe adotar está [...] tendo a oportunidade de escolher diretamente o amor..." (Carlos, juiz).

Para Levinzon (2009), a etimologia da palavra adoção significa consideração, cuidado, escolha e reestabelecimento de vínculos. Em uma pesquisa realizada com pais por adoção, os 
pesquisadores encontraram características como o amor e o desejo de exercer a parentalidade como sendo motivadores para a adoção (CECÍLIO; SCORSOLINI-COMIN, 2016).

Outros três entrevistados ressaltaram a adoção como um ato fundamental para estabelecer relações de afeto, apontando para a necessidade de todos os pais adotarem os seus filhos, sendo consanguíneos ou não. A própria Cartilha Passo a Passo publicada pela Associação dos Magistrados do Brasil (2009) diz que tanto a adoção jurídica quanto a parentalidade consanguínea não garantem que aconteça uma adoção afetuosa entre pais e filhos. Schettini, Amazonas e Dias (2006, p. 287) ressaltam que "a adoção é a única possibilidade de se constituir uma verdadeira parentalidade e a única maneira de genitores tornarem-se pais." Ou seja, todos os pais devem adotar seus filhos, consanguíneos ou não, reconhecendo que a adoção deve ser vista como um ato de reciprocidade em que os filhos também devem adotar seus pais (GONDIM et al., 2008), sendo o amor uma construção que independe da consanguinidade para acontecer (WEBER, 1998).

Ainda sobre os significados atribuídos, outros profissionais $(n=7)$ percebem a adoção como um modo de ter filhos devido à impossibilidade biológica. A adoção é uma "forma de ter filhos. [...] chega um ponto da vida em que se deseja ter filhos, e se há um impedimento biológico para que isso aconteça, a adoção é o caminho" (Maria Luiza, psicóloga).

A questão da infertilidade como justificativa para a adoção também emergiu de modo mais velado em outros participantes. Apesar de Schettini, Amazonas e Dias (2006) apontarem que a adoção já não é mais vista como uma segunda via para a parentalidade, fica claro na fala desses profissionais que a adoção aparece como uma forma alternativa de ter filhos, reforçando a adoção por indivíduos ou casais com infertilidade, o que permeia o imaginário social.

Em algumas falas é possível perceber que ainda existe a cultura de candidatos à adoção procurarem por crianças menores. Ebrahim (2001) afirma que a sociedade ainda acredita que adotar crianças menores é melhor, pois é possível esconder suas origens, acreditando que aquelas que não sabem sobre sua adoção são menos "problemáticas" e propensas a dificuldades no futuro. As crianças consideradas mais velhas, principalmente as que passaram por instituições de acolhimento, são interpretadas como tendo "maus hábitos" e maior chance de terem problemas emocionais. Uma pesquisa realizada por Cecílio e Scorsolini-Comin (2016) com pais por adoção e consanguíneos apontou que os filhos, 
independentemente de serem consanguíneos ou não, têm suas próprias características e personalidade. A partir disso, pode-se concluir que adotar um bebê não é um fator determinante para que o filho se pareça mais com os pais por adoção.

Uma profissional relatou que algumas vezes é bastante complicado fazer a vinculação genuína e sem conflitos entre o adotado e o adotante, pois essas crianças/adolescentes trazem consigo uma bagagem de abandono. Podemos ver essa referência na seguinte fala: "Adoção [...] é você assumir uma criança/adolescente com a história que ele tem, com a bagagem que ele vem [...] construir uma nova história com aquela pessoa" (Ana, assistente social)."

Oliveira (2014) realizou uma pesquisa com a equipe do setor técnico do Judiciário e apontou a preocupação de alguns técnicos sobre a necessidade dos adotantes considerarem a história da criança, não negando as suas origens. Além disso, os participantes dessa pesquisa falam da importância de os pais saberem o que aconteceu no passado de seus filhos para que eles possam se colocar no lugar dos mesmos, podendo, a partir disso, proporcionar um ambiente diferente e mais afetivo para eles.

Ressalta-se que tanto pais quantos os filhos por adoção carregam uma bagagem préadotiva, mas no caso da criança há um rompimento de vínculo com a família de origem. Espera-se que os pais por adoção possam oferecer uma base para que essa criança possa continuar a se desenvolver sem traumas desse primeiro laço de afeto que foi rompido, sem tentar apagar a história da criança (OTUKA; SCORSOLINI-COMIN; SANTOS, 2009; SCHETINNI et al., 2006). Em relação aos pais, além de um histórico de construção dessa parentalidade há, muitas vezes, a dificuldade de relevar ao filho a condição da adoção (GOMES; IYAMA, 2001).

Ressalta-se a importância de que pais e filhos conheçam a história uns dos outros para que eles possam compreender qual o seu significado no círculo familiar. Para Levinzon (2009), o ato de adotar simboliza para os filhos que não puderam ser criados por seus pais consanguíneos a oportunidade de inserção em uma família, um lar permanente e uma base social, os quais podem preencher suas necessidades de desenvolvimento, bem como proporcionar segurança, afeto, cuidados específicos e vinculações seguras. Desse modo, em relação à família que se coloca aberta para adoção, tal processo responde ao desejo de ter e criar filhos, seja pela impossibilidade biológica ou a vontade de cuidar de crianças ou adolescentes com quem não possuem laços genéticos (LEVINZON, 2009). Além desses fatores, 
Cecílio e Scorsolini-Comin (2016) apontam que as pessoas também procuram a adoção considerando que esta seja um ato de altruísmo, de amor e de caridade.

A partir do que foi exposto, pode-se compreender que o que os técnicos do Sistema de Justiça priorizam em uma avaliação de candidatos à adoção difere entre si de acordo com suas experiências, sejam elas pessoais, profissionais ou por conceitos que foram internalizados (OLIVEIRA, 2014). A atuação do profissional acontece de acordo com suas vivências e subjetividades, ainda que reconheçam a ancoragem desses aspectos na legislação vigente. Alguns dos entrevistados priorizavam mais os vínculos afetivos enquanto outros se preocupam com o lugar que a criança vai ocupar na família, por exemplo.

Com isso, é possível perceber que a adoção é um assunto complexo que diz da subjetividade do técnico avaliador e o que ele apreendeu durante a vida, não se baseando apenas nos critérios descritos pela legislação ou nas orientações relativas ao seu cargo e à sua profissão. Embora essa abertura possa ser positiva no sentido de tornar a legislação viva, com possibilidades de releituras e interpretações, também lança dificuldades, haja vista que nem sempre se pode apreender, de fato, os pressupostos que orientam o processo adotivo desde a avaliação até a decisão pela recomendação ou não da adoção. Esses elementos precisam ser amadurecidos e clarificados dentro da equipe e também comunicados aos envolvidos. Assim, sugere-se que esses critérios possam ser melhor explicitados e reconhecidos pelas equipes, sendo constantemente revisitados e questionados (CECÍLIO; SCORSOLINI-COMIN, 2018a). Sobretudo, que esses critérios estejam sempre subsidiados à legislação, ainda que haja aberturas para diferentes interpretações, em um processo dinâmico, assim como as relações observadas em família.

\section{Repercussões da atuação com processos de adoção}

Quando esses profissionais foram questionados sobre como é trabalhar com a adoção, dez disseram que gostam bastante e consideram essa atuação gratificante. Alguns salientaram ser ainda mais prazeroso quando eles conhecem o histórico da criança que está sendo adotada e acompanharam a trajetória dela até conseguir uma família substituta. Outros participantes $(n=4)$ consideram que trabalhar com esse tema é a melhor parte da atuação, pois na área da infância e juventude existem outras demandas consideradas mais desgastantes, como nos casos de violência e de negligência. Eles consideram a adoção como 
um "recomeço" (Carolina, juíza) e como o que "há de bonito, o que se há de gostoso" (Fernando, juiz) dentro desse trabalho no Sistema de Justiça, considerado muito exaustivo.

Em contrapartida, 12 entrevistados mencionaram que essa é uma área muito frustrante, pois às vezes os pretendentes não querem adotar crianças negras, que apresentem problemas de saúde ou alguma deficiência, irmãos ou com idade um pouco acima do que foi estabelecido por eles (BORGES; SCORSOLINI-COMIN, 2020; MARIANO; ROSSETTI-FERREIRA, 2008). Consideram que esse tema é desafiador, pois estão lidando diretamente com o futuro de uma criança, mas se torna gratificante quando a adoção é concretizada. Um dos profissionais aponta que o trabalho que eles realizam é:

[...] difícil porque você percebe a falência de uma família na questão dos cuidados com a criança, mas ao mesmo tempo é gratificante porque você consegue recolocar aquela criança num outro ambiente saudável pra que ela possa se desenvolver (Joaquim, promotor).

Em relação à repercussão do trabalho com adoção na vida desses entrevistados, alguns $(n=5)$ perceberam mudanças em si a partir do momento em que passaram a trabalhar diretamente com o processo de habilitação da adoção e colocação em família substituta. A fala de uma entrevistada chama a atenção quando ela relata que antes de começar a trabalhar com adoção a idealizava bastante "[...] aquela ideia de romancear o ser pai e ser mãe, eu acho que eu ainda tinha. E eu percebo que é uma criança como outra qualquer, que não é um ato de caridade nossa" (Flavia, psicóloga). De acordo com Weber (2001), os técnicos que atuam no Sistema de Justiça não conseguem tomar decisões neutras, pois não é possível explicar a realidade humana apenas a partir de seus conhecimentos teóricos ou de posicionamentos legais. Nesse sentido, a abertura para a consideração da subjetividade de um modo maduro nesse processo pode permitir avaliações mais seguras e desfechos mais positivos.

Considerando que esse trabalho coloca em jogo as emoções dos profissionais envolvidos, oito deles acreditam que suas subjetividades influenciam no seu trabalho, considerando ser difícil deixá-las de lado. Para um dos promotores entrevistados, "as coisas são misturadas, o meu trabalho profissional, vem com o meu pessoal (Joaquim). A fala de uma profissional de outra área vem no sentido de complementar esse posicionamento: "eu falo de um lugar da minha história, do que aconteceu, de onde eu entrei, o que eu estudei e qual família que eu tive" (Fabiana, psicóloga). Mas é importante que os profissionais consigam ter 
consciência dessa influência para que possam tomar mais cuidado no processo de habilitação dos casais. Nesse sentido, uma técnica coloca que "eu acho que a gente tem que tomar conhecimento dessas coisas [...] saber o que me toca, como me toca e saber sair desse lugar pra conseguir conhecer o outro, de uma maneira neutra" (Beatriz, psicóloga).

Pensando sobre essas falas, uma pesquisa feita por Oliveira (2014) sobre a avaliação dos pretendes à adoção com os psicólogos que compõem a equipe técnica do Judiciário revelou que os fatores pessoais desses profissionais influenciam na forma de avalição realizada por eles. No presente estudo, oito entrevistados alegaram ter conhecimento de colegas de trabalho que se deixaram influenciar por suas crenças e dogmas no momento de habilitar ou de fazer a colocação de uma criança em uma família substituta. A atuação dos avaliadores ainda é permeada por questões socialmente constituídas, abrindo precedentes para questões subjetivas dos profissionais (CECÍLIO; SCORSOLINI-COMIN, 2018a, 2018b). Nesse sentido, um profissional fala que:

[...] eu entendo também que nós tenhamos limites em relação à nossas questões emocionais, [...] e acho que a gente tem que ter essa condição de alegar que não se sente em condições de fazer uma determinada avaliação. [...] eu não teria dúvida que se eu me sentisse tocada em algum tema, e fosse prejudicar a avaliação, de colocar nos laudos de que me sentia suspeita e se não pudesse falar o motivo eu não falaria, mas pediria a nomeação de outro profissional (Victória, psicóloga).

Nessa fala percebe-se que a participante aponta para a importância dos profissionais se conhecerem e reconhecerem seus limites para que as avaliações não sejam permeadas por visões pessoais. Nesse sentido, Ximenes e Scorsolini-Comin (2018) apontam que é imprescindível que esses profissionais percebam suas visões sobre o que entendem como sendo adoção, parentalidade e família, uma vez que apontar se os pretendentes estão ou não aptos a adoção não é uma decisão neutra. O reconhecimento da subjetividade que atravessa e compõe esse fazer profissional pode permitir o desenvolvimento de avaliações mais amadurecidas e seguras, ensejando desfechos mais positivos para as partes envolvidas.

Todavia, na maioria das vezes, essas falas estão relacionadas a casais do mesmo sexo que desejam experienciar a parentalidade por meio da adoção. No que diz respeito a isso, a fala de uma profissional chama a atenção: "Ela tem preconceito, ela falava mesmo, que tinha preconceito, não conseguia, tinha o lado da religião, então era difícil pra ela" (Neuza, psicóloga). Principalmente no que diz respeito ao trabalho do psicólogo, Ximenes e Scorsolini- 
Comin (2018) afirmam que a função desses profissionais é avaliar se os postulantes estão aptos a adotar e qual será o benefício da adoção para as crianças, e não fazer julgamentos morais a respeito da orientação sexual dos pretendentes.

Por fim, duas profissionais abordaram a falta de formação continuada dos profissionais que trabalham com adoção, tanto a equipe técnica quanto promotores e juízes. Outra profissional aponta que o tema adoção necessita de muito estudo teórico,

[...] mas principalmente, sensibilidade e compreensão por parte de nós que atuamos na parte jurídica. [...] a legislação está longe de ser aplicada, principalmente por conta do preconceito da sociedade e despreparo dos profissionais que trabalham na adoção (Alice, promotora).

Em relação ao papel dos profissionais do Direito, Cecílio e Scorsolini-Comin (2018b) apontam que, na maioria das vezes, eles acabam se apoiando nos laudos feitos pela equipe técnica psicossocial. Esse fator também ocorre devido ao fato de que promotores e juízes não costumam ter contato direto com os candidatos na avaliação, o que pode ser considerado com insuficiente para deferir ou indeferir o processo.

A literatura sugere o acompanhamento desses profissionais devido ao sofrimento psíquico decorrente da gravidade e complexidade das demandas, como casos de violência, questões sociais e de abandono. Ainda, é importante que haja maior amparo e referencial para as avaliações e as decisões em relação a um processo tão significativo quanto a adoção (OLIVEIRA, 2014; SILVA et al., 2017). Apesar de se respaldarem na legislação, a avaliação e a tomada de decisão não ocorrem apartadas de elementos subjetivos que compõem o fazer no Sistema de Justiça.

Com base no que foi exposto nesse tema, há a necessidade de serem tomadas medidas de prevenção que possibilitem que os técnicos, juízes e promotores compreendam e reconheçam a influência de suas subjetividades no âmbito do trabalho. Para além de uma formação específica e contínua, as próprias equipes podem se articular em termos da proposição de cursos, rodas de conversa e mesmo supervisões, a fim de que possam compor um repertório de atuações, discutindo casos, posicionamentos e encaminhamentos de modo mais seguro e amparado. As questões pessoais que emergem ao longo do processo podem e devem vir à baila, mas de um modo que possam ser refletidas, discutidas e localizadas em relação à legislação vigente. Assim, não se busca necessariamente uma atuação integralmente 
neutra, isenta e impossível de ser influenciada por aspectos que transcendem o trabalho, mas que esse processo possa ser reconhecido, discutido e amadurecido, priorizando uma avaliação ética, séria, comprometida e que se respalde nos pressupostos legais que envolvem a adoção em nosso país.

\section{Considerações Finais}

As mudanças na legislação e as variadas formas de configurações familiares que vêm ganhando maior visibilidade e pleiteando a adoção estão transformando rapidamente a forma como esse ato é visto socialmente. Apesar de leis como o ECA e a lei 12.010/09 destacarem o melhor interesse da criança, elas não especificam como deveria ser o processo de escolha dos pretendentes. Com isso, abrem-se precedentes para que os profissionais do Sistema de Justiça, no caso psicólogos, assistentes sociais, juízes e promotores, interpretem esse ato de diversas formas, sendo que na maioria das vezes eles acabam esbarrando em suas percepções pessoais para definir a adoção, podendo se deixar influenciar por suas subjetividades e posicionamentos pessoais. Além disso, a falta de capacitação também pode contribuir para a expressão de alguns preconceitos nesse processo avaliativo e decisório, por exemplo, desconstruindo os pressupostos da adoção.

A maioria dos entrevistados alegou que o ato de adotar transcende o que é descrito pela legislação, considerando aspectos afetivos (cuidado, desejo, amor) como fatores muito importantes para a habilitação dos pretendentes. Apontaram que a adoção é um movimento de reciprocidade em que pais e filhos devem aceitar suas histórias passadas e se adotarem afetivamente. Além disso, também foi possível perceber que ainda resta em alguns profissionais a visão do filho como sendo algo que vai suprir as necessidades de casais com infertilidade.

Apesar de alguns profissionais do Sistema de Justiça alegarem que deve haver uma separação entre questões pessoais e profissionais, foi possível perceber que as suas subjetividades atravessam de modo inequívoco as suas atuações. Esse fator configura uma interferência direta na forma como cada um deles interpreta o que é proposto pela legislação vigente. Evidencia-se, portanto, a necessidade de especialização e maior amparo dos profissionais que trabalham nessa área não no sentido de uma recusa à subjetividade, mas de um amadurecimento acerca desse elemento e do próprio fazer. 
As concepções sobre adoção puderam aqui ser trazidas à baila e discutidas não na perspectiva de apontar falhas ou imperícias nos processos, mas como um elemento que deve ser discutido e considerado quando se trabalha com a temática. A atuação ética não significa a anulação dos aspectos pessoais e subjetivos que atravessam a construção do profissional e de sua atuação na área. Esses aspectos podem e devem ser considerados. No que tange às investigações vindouras, outros estudos podem ser endereçados a esses profissionais, compondo um repertório de práticas e discussões que devem ser constantemente revisitadas no fazer profissional, permitindo a emergência de avaliações seguras e potentes no sentido de permitirem adoções bem-sucedidas e que priorizem o bem-estar das crianças e adolescentes envolvidos.

\section{Referências}

ASSOCIAÇÃO DOS MAGISTRADOS DO BRASIL. Cartilha passo a passo. 2009. Disponível em: https://www.defensoria.pb.def.br/criative/Documentos/Cartilha-adocaopassoapasso.pdf. Acesso em: 15 fev. 2018

BORGES, C. A. P; SCORSOLINI-COMIN, F. As adoções necessárias no contexto brasileiro: características, desafios e visibilidade. Psico-USF, Campinas, v. 25, n. 2, p. 307-320, 2020.

BRAUN, V.; CLARKE, V. Using thematic analysis in psychology. Qualitative Research in Psychology, [S. I.], v. 3, n. 2, p. 77-101, 2006.

BRASIL. Lei n. 8.069, de 13 de julho de 1990. Dispõe sobre o Estatuto da Criança e do Adolescente e dá outras providências. Diário Oficial da União: seção 1, Brasília, DF, p. 13563, 16 jul. 1990.

BRASIL. Lei n. 12.010, de 3 de agosto de 2009. Dispõe sobre adoção. Diário Oficial da União: Seção 1, Brasília, DF, p. 1, 4 ago. 2009.

CAMPOS, N. M. V.; COSTA, L. F. A subjetividade presente no estudo psicossocial da adoção. Psicologia: Reflexão e Crítica, Porto Alegre, v. 17, n. 1, p. 95-104, 2004.

CECÍLIO, M. S.; SCORSOLINI-COMIN, F. Parentalidades adotiva e biológica e suas repercussões nas dinâmicas conjugais. Psicologia: Ciência e Profissão, Brasília, v. 36, n. 1, p. 171-182, 2016.

CECÍLIO, M. S.; SCORSOLINI-COMIN, F.. Avaliação de candidatos pretendentes no processo de habilitação para adoção: revisão da literatura. Psico-USF, Itatiba, v. 23, p. 497-511, 2018a.

CECÍLIO, M. S.; SCORSOLINI-COMIN, F. Adoção por casais do mesmo sexo na perspectiva de profissionais do Sistema de Justiça. Estudos de Psicologia, Natal, v. 23, n. 4, p. 392-403, 2018b. 
COSTA, N. R. do A.; ROSSETTI-FERREIRA, M. C. Tornar-se pai e mãe em um processo de adoção tardia. Psicologia: Reflexão e Crítica, Porto Alegre, v. 20, n. 3, p. 425-434, 2007.

EBRAHIM, S. G. Adoção tardia: altruísmo, maturidade e estabilidade emocional. Psicologia: Reflexão e Crítica, Porto Alegre, v. 14, n. 1, p. 73-80, 2001.

FERREIRA, L. A. M. Aspectos jurídicos da intervenção social e psicológica no processo de adoção. Justitia, v. 63, n. 196, p. 120-135, 2001.

GOMES, I. C.; IYAMA, R. Atendimento breve de orientação psicanalítica a pais de crianças adotivas. Boletim de Psicologia, v. 114, n. 51, p. 109-121, 2001.

GONDIM, A. K.; CRISPIM, C. S.; FERNANDES, F. H. T.; ROSENDO, J. C.; BRITO, T. M. C. de; OLIVEIRA, U. B. de; NAKANO, T. de C.. Motivação dos pais para a prática da adoção. Boletim de Psicologia, São Paulo, v. 58, n. 129, p. 161-170, 2008.

GONZÁLEZ R., Fernando. O social na psicologia e a psicologia social. Petrópolis: Vozes, 2004.

LEVINZON, G. K. Adoção. 3. ed. São Paulo: Casa do Psicólogo, 2009.

MARIANO, F. N.; ROSSETTI-FERREIRA, Maria Clotilde. Que perfil da família biológica e adotante, e da criança adotada revelam os processos judiciais? Psicologia: Reflexão e Crítica, Porto Alegre, v. 21, n. 1, p. 11-19, 2008.

MERÇON-VARGAS, E. A.; ROSA, E. M.; DELL'AGLIO, D. D. A produção científica e os aspectos legais no âmbito da adoção nacional e internacional. In: SCORSOLINI-COMIN, F.; PEREIRA, A. K.; NUNES, M. L. T. (org.). Adoção: legislação, cenários e práticas. São Paulo: Vetor, 2015. p. 29-47.

OLIVEIRA, R. R. Os critérios e estratégias utilizados por assistentes técnicos judiciários psicólogos na avaliação de pretendentes à adoção. 2014. Dissertação (Mestrado em Psicologia) - Universidade de São Paulo, São Paulo, 2014.

OTUKA, L. K.; SCORSOLINI-COMIN, F.; SANTOS, M. A.. A configuração dos vínculos na adoção: uma atualização no contexto latino-americano. Revista Brasileira de Crescimento $e$ Desenvolvimento Humano, São Paulo, v. 19, n. 3, p. 475-486, 2009.

PEREIRA, A. K.; AZAMBUJA, M. R. F. de. História e legislação da adoção no Brasil. In: SCORSOLINI-COMIN, F.; PEREIRA, A. K.; NUNES, M. L. T. (org.). Adoção: legislação, cenários e práticas. São Paulo: Vetor, 2015. p. 17-27.

SCHETTINI, S. S. M.; AMAZONAS, M. C. L. de A.; DIAS, C. M. de S. B. Famílias adotivas: identidade e diferença. Psicologia em Estudo, Maringá, v. 11, n. 2, p. 285-293, 2006.

SILVA, P. S. da; CASSARINO-PEREZ, L.; SARRIERA, J. C.; FRIZZO, G. B. A equipe psicossocial na colocação da criança nos processos de adoção. Psicologia: Ciência e Profissão, Brasília, v. 37, n. 3, p. 608-623, 2017. 
SÃO PAULO. Tribunal de Justiça. Atuação dos profissionais de Serviço Social e Psicologia. São Paulo: Tribunal de Justiça, 2007. Disponível em:

http://www.tjsp.jus.br/Download/Corregedoria/pdf/manual_de_procedimentos.pdf. Acesso em:20 maio 2018.

VALÉRIO, T. A. de M.; LYRA, M. C. D. P. Significados ambivalentes no processo de adoção: um estudo de caso. Psicologia em Estudo, Maringá, v. 21, n. 2, p. 337-348, 2016.

WEBER, L. N. D. Laços de ternura. Curitiba: Juruá, 1998.

WEBER, L. N. D. Pais e filhos por adoção no Brasil. Curitiba: Juruá, 2001.

XIMENES, F.; SCORSOLINI-COMIN, F. Adoção por casais do mesmo sexo: relatos de psicólogos do Judiciário. Estudos Interdisciplinares em Psicologia, Londrina, v. 9, n. 1, p. 6585, 2018. 